\title{
A PEDAGOGIA HISTÓRICO-CRÍTICA E A FORMAÇÃO CONTINUADA DE PROFESSORES NA REDE MUNICIPAL DE ENSINO DE CURITIBA
}

\author{
Alboni Marisa Dudeque Pianovski Vieira ${ }^{\mathrm{i}}$
}

\section{RESUMO}

$\mathrm{O}$ artigo tem por objeto discutir as políticas públicas de formação continuada dos professores na Rede Municipal de Ensino de Curitiba, no período 1963-1996, tema que vem sendo estudadona linha de pesquisa "História e Políticas da Educação", do Programa de Pós-Graduação - Mestrado e Doutorado em Educação, da Pontifícia Universidade Católica do Paraná. O recorte histórico ora selecionado abrange o período 1986-1989, relativo à gestão do prefeito Roberto Requião, quando se implantou o $4^{\circ}$ Plano Educacional, inspirado nas ideias pedagógicas de Saviani. O objetivo do trabalho, portanto, é refletir sobre as implicações daadoção da pedagogia histórico-crítica na formação continuada de professores da Rede Municipal de Ensino de Curitiba, nesse período. Do ponto de vista metodológico, trata-se de pesquisa de caráter documental, que teve apoio em relatórios disponíveis no Arquivo da Rede Municipal de Ensino de Curitiba, contando com a contribuição teórica de Mello (1995) e Saviani (2008), entre outros. Os resultados obtidos evidenciaram a ênfase da formação continuada dos professores voltada ao desenvolvimento das competências técnicas e políticas necessárias à execução da proposta pedagógica implantada.

Palavras-chave: pedagogia histórico-crítica; formação continuada; Rede Municipal de Ensino de Curitiba.

\section{THE HISTORICAL-CRITICAL PEDAGOGY AND THE CONTINUOUS TEACHER TRAINING AT THE MUNICIPAL SCHOOL NETWORK OF CURITIBA}

ABSTRACT

This article aims to discuss the public policies concerning the continuous training of teachers from the Municipal School Network of Curitiba, during the period from 1963 to 1996. The topic has been examined in the research line called "History and Education Policies" of the Postgraduate Program - Masters and Doctorate in Education at the Pontifical Catholic University of Paraná. The period analyzed includes the time lapse from 1986 to 1989, under the administration of Mayor Roberto Requião, when they implemented the 4th Educational Plan, inspired by the pedagogical ideas of Saviani. Therefore, the objective of this article is to reflect on the implications of adopting the historical-critical pedagogy in the continuous teacher training seen at the Municipal School Network of Curitiba during this period. From the methodological point of view, it is documentary research, supported by reports available at the file of the Municipal School Network of Curitiba, with the theoretical contribution of Mello (1995) and Saviani (2008), among others. The results showed the emphasis of continuous teacher training inclined towards the development of technical and political skills needed to implement the established pedagogical proposal.

Keywords: historical-critical pedagogy; continuous education; Municipal School Network of Curitiba. 


\section{INTRODUÇÃO}

O início da década de 1980 foi decisivo na história nacional, estadual e municipal, com mudanças radicais que afetaram a estrutura da sociedade brasileira e determinariam marcantes consequências futuras.

Dentro da euforia das liberdades políticas que vinham sendo (re)conquistadas, após longo período de regime militar, no Paraná e em Curitiba o Partido do Movimento Democrático Brasileiro (PMDB) conseguira eleger seus candidatos. Assim, José Richa e Maurício Fruet assumiram, respectivamente, os cargos de Governador do Estado e de Prefeito de Curitiba.

O modelo econômico implantado no Brasil pelos militares, depois de 1964, "concentrador de renda, excludente, voltado para o mercado externo" (GOHN, 1991, p. 10), porém, continuava o mesmo, nos anos 80. Essa situação era de tal forma grave e complexa que, mesmo a retomada do processo de crescimento, após 1984, não foi suficiente para recuperar os indicadores dos anos 70. "Alguns analistas chegam a denominar essa fase de 'a década perdida'. Perdeu-se impulso e esgotou-se o modelo de crescimento", explica Gohn (1991, p. 10). Nesses anos, de acordo com Gohn (1991), porém, é possível identificar não apenas perdas, mas também avanços significativos no plano sócio-político, com a restauração da vida democrática.

A administração do PMDB municipal representava, em Curitiba, como na maior parte das localidades, a expectativa popular de mudanças, diante da profunda crise econômica e social que se instalara, com boa parcela da população vivendo abaixo dos níveis mínimos de subsistência. Como a política econômica do Estado nacional mantiverase a mesma dos anos anteriores, os governos estadual e municipal, conquanto acenassem com avanços significativos no plano sócio-político, tiveram necessidade de conviver com práticas retrógradas que lutavam contra sopros de maior participação e responsabilidade.

De acordo com a proposta de democracia participativa, que era o lema da campanha do PMDB, o prefeito Maurício Fruet, em sua gestão na área educacional, adotou uma política de superação da postura tecnicista, exigindo uma ação mais crítica e democrática por parte dos professores. Estimulou a valorização da participação da comunidade no processo educativo, a autonomia da escola, o planejamento dinâmico, a interação entre o Estado e a sociedade e a promoção da democracia. Na gestão seguinte, do prefeito Roberto Requião, esse trabalho teve continuidade, com uma política cada vez mais comprometida com a maioria da população, que considerava as necessidades diagnosticadas junto às escolas.

A partir desse retorno à democracia podem ser identificados, portanto, dois períodos histórico-educacionais bastante significativos, elencados na classificação elaborada por Miguel e Vieira (2006), consoante seguem:

1. 1983-1985 - Período correspondente à gestão de Maurício Fruet, como prefeito, no decorrer do qual foi publicado o manifesto "Políticas da Educação para uma Escola Aberta", elaborado a partir das discussões e reflexões entre os profissionais da Rede Municipal de Ensino de Curitiba (RME), evidenciando o compromisso expresso com a população de baixa renda.

2. 1986-1989 - Período correspondente à gestão de Roberto Requião, como prefeito, durante o qual foi implantado o $4^{\circ}$ Plano de Educação do Município de Curitiba, elaborado pela Secretaria Municipal de Educação, com fundamento na pedagogia histórico-crítica.

Essas mudanças de caráter político estimularam discussões sobre o currículo que vinha sendo adotado nas escolas do município, o que exigiu o estabelecimento de uma 
política efetiva de formação continuada do corpo docente, operacionalizada pela Divisão de Treinamento Pedagógico da Diretoria de Educação da RME, que atuava desde 1979 e que, mais tarde, foi substituída, na gestão do prefeito Roberto Requião, pela Divisão de Aperfeiçoamento Profissional. Esses dois setores da Secretaria Municipal de Educação propiciaram destacada quantidade de eventos voltados à formação continuada dos docentes.

Com tais pressupostos, este trabalho se insere na linha de pesquisa "História e Políticas da Educação", do Programa de Pós-Graduação - Mestrado e Doutorado - em Educação, da Pontifícia Universidade Católica do Paraná, que, nos últimos anos, vem estudando as políticas públicas de formação continuada dos professores da Rede Municipal de Ensino de Curitiba. O recorte histórico compreende o período 1986-1989, quando se implantou o $4^{\circ}$ Plano Educacional no município, inspirado nas ideias pedagógicas de Saviani, e tem por objetivo refletir sobre as implicações da adoção da pedagogia históricocrítica na formação continuada de professores na RME.

Do ponto de vista metodológico, trata-se de pesquisa de caráter documental, que teve apoio em relatórios disponíveis no Arquivo da Rede Municipal de Ensino, contando com a contribuição teórica de Mello (1995), Tomacheski (2003) e Saviani (2008), entre outros. Pela análise dos documentos, "o historiador não exige que as pessoas acreditem em sua palavra [...], mas fornece ao leitor a possibilidade de verificar suas afirmações" (PROST, 2014, p. 55).

Lüdke e André (1986, p. 38) consideram que a análise documental é uma valiosa técnica de abordagem de dados qualitativos, complementando informações obtidas por outras técnicas e desvelando aspectos novos de um tema ou problema. Tem-se por certo que "a história não é jamais a repetição do arquivo", como observa Farge (2009, p. 75), "mas desinstalação em relação a ele".

Os resultados obtidos evidenciaram a ênfase da formação continuada dos professores voltada ao desenvolvimento das competências técnicas e políticas necessárias à execução da proposta pedagógica implantada.

\section{DESENVOLVIMENTO}

\section{Um currículo inspirado na pedagogia histórico-crítica}

As Diretrizes Gerais da Rede Municipal de Ensino de Curitiba para o período 1983-1985, contrariamente à concepção liberal que vigia até então, propuseram não mais formar os alunos como "instrumentos a serem manipulados pelo sistema capitalista", mas sim, dotá-los "dos requisitos básicos para a sobrevivência num mundo em mudança, aliados ao despertar de uma consciência crítica e atuante na sociedade a que pertencem" (CURITIBA, 1983, s.p.).

$\mathrm{Na}$ sociedade capitalista, a educação reproduz os interesses do capital, propiciando aos trabalhadores o acesso ao mínimo do saber necessário para que possam produzir. Para não reproduzir esse modelo liberal, seria necessário que a escola desse aos alunos o acesso ao saber sistematizado, impulsionando a transformação da sociedade, e não apenas sendo um elemento de reprodução (SAVIANI, 2008). Nessa nova concepção,o professor deveria buscar formas, processos e métodos para que os alunos pudessem transformar o saber elaborado em um saber que lhes possibilitasse A pedagogia histórico- 
crítica foi assumida, então, como a que melhor se identificava com a concepção de educação adequada para o Município de Curitiba. De acordo com Duarte (2001):

\begin{abstract}
A Pedagogia Histórico-crítica, tal como ela encontra-se esboçada, na forma de primeiras aproximações, nos trabalhos de Dermeval Saviani, é a concepção pedagógica que entendemos ser compatível com nossa fundamentação filosófica e com nosso compromisso político, bem como aquela com base na qual entendemos ser possível apresentar uma crítica radical ao 'aprender a aprender' e às interpretações neoliberais e pós-modernas [...] (DUARTE, 2001, p. 4).
\end{abstract}

Analisando a evolução desse processo, pode-se dizer que as raízes da pedagogia histórico-crítica concebida num sentido amplo estão localizadas no movimento francês de 1968, que estimulou o surgimento das teorias críticas - da violência simbólica, de Bourdieu e Passeron (1970), e da escola capitalista, de Baudelot e Establet (1971) -, as quais passaram a ser conhecidas e estudadas no Brasil, e, de alguma forma, como destaca Saviani (2008, p. 66), impulsionaram "a crítica ao regime autoritário e à pedagogia autoritária desse regime, a pedagogia tecnicista". Análises e reflexões sobre a educação foram alimentadas pelas ideias críticas que, embora não apresentassem uma proposta de intervenção prática na educação, faziam a crítica da educação existente. A partir dessa crítica, os educadores perceberam que era preciso buscar formas de atuar criticamente na prática pedagógica, indo além do campo teórico e crítico. Coube a Saviani, que se dedicou intensamente à elaboração de uma concepção teórica que atendesse a essa exigência, em 1979, chegar à elaboração de uma concepção que denominou "histórico-crítica", e que "procurava reter o caráter crítico de articulação com as condicionantes sociais que a visão reprodutivista possui, vinculado, porém, à dimensão histórica que o reprodutivismo perde de vista" (SAVIANI, 2008, p. 70). A contraditoriedade da função política da educação e seu cumprimento pela mediação da competência técnica, demonstrada por Guiomar de Mello, em sua tese de doutorado (MELLO, 1995), colaborou para definir o entendimento da nova concepção. Ficava claro, assim, que os professores se mostravam incompetentes do ponto de vista técnico, sem condições de transmitirem o saber escolar às camadas dominadas, porque a competência técnica exige também a competência política, que não era privilegiada pelo tecnicismo na formação docente.

O saber sistematizado, o conteúdo, de acordo com a pedagogia histórico-crítica, não interessava à pedagogia como tal, mas como "um meio para o crescimento do aluno", deixando para o cientista o conhecimento como um fim (SAVIANI, 2008, p. 74). À formação dos alunos não interessava assimilar o saber enquanto resultado, mas sim a aprendizagem do processo de sua produção, historicamente considerada.

Elaborando uma síntese da tarefa a que se propõe a pedagogia histórico-crítica, relativamente à educação escolar, Saviani (2008) menciona que ela implica em:

a) Identificação das formas mais desenvolvidas em que se expressa o saber objetivo produzido historicamente, reconhecendo as condições de sua produção e compreendendo as suas principais manifestações, bem como as tendências atuais de transformação.

b) Conversão do saber objetivo em saber escolar, de modo que se torne assimilável pelos alunos no espaço e tempo escolares.

c) Provimento dos meios necessários para que os alunos não apenas assimilem o saber objetivo enquanto resultado, mas apreendam o processo de sua produção, bem como as tendências de sua transformação (SAVIANI, 2008, p. 9). 
Na pedagogia histórico-crítica, a responsabilidade da escola em relação ao saber sistematizado, sua transmissão e assimilação, é extremamente relevante. Para bem desempenhar essa tarefa, os professores devem possuir competência técnica, não no sentido tecnicista, mas envolvendo o domínio adequado do saber escolar a ser transmitido, um entendimento das múltiplas relações entre os vários aspectos da escola, uma compreensão das relações entre o preparo técnico, a organização da escola e os resultados de sua ação, bem como uma compreensão mais ampla das relações entre a escola e a sociedade.

Foram esses os fundamentos teóricos que justificaram a ênfase na formação continuada dos professores da Rede Municipal de Ensino de Curitiba, que necessitavam discutir não apenas os aspectos técnicos de sua prática, mas também a compreensão da história, partindo das condições materiais da existência humana.

Ao assumir a Prefeitura Municipal de Curitiba, em 1986, Roberto Requião mostrou-se compromissado com a democratização do conhecimento e a transformação da sociedade. Dentre suas metas, a que se referia à democratização do conhecimento pela ampliação da oferta escolar previa, como sub-metas que interessavam à formação continuada do professor, o apoio técnico-pedagógico às escolas e o aperfeiçoamento profissional permanente.

O Currículo Básico elaborado em 1988, que havia sido inspirado na pedagogia histórico-crítica, veio sintetizar as propostas de ação da Secretaria Municipal de Educação, que eram voltadas ao processo de democratização da sociedade brasileira. De acordo com Tomacheski,

O Currículo Básico/88 da RME de Curitiba representa um projeto pedagógico, produto de estudos, reflexões e debates, sistematizados no $4^{\circ}$ Plano de Educação, gestão 85-88, reunindo os esforços de vários profissionais da própria rede e de algumas universidades. Esse trabalho representou um marco importante na história da educação municipal que, nesse processo histórico, foi sendo realimentado pelas políticas educacionais que se sucederam (TOMACHESKI, 2003, p. 21).

A autora destaca, ainda, que "o caráter inovador das políticas municipais" serviu de inspiração para as políticas estaduais de educação.

Com a aprovação do Currículo Básico, inúmeras oportunidades de formação continuada foram ofertadas aos professores, envolvendo atividades voltadas ao planejamento do trabalho docente e cursos ministrados conforme solicitação das escolas, além de oficinas e grupos de estudos. O estabelecimento da semana móvel favorecia a organização de oficinas e cursos, bem como a formação de grupos de estudos, sem prejuízo do atendimento dos alunos. Era fundamental que os docentes e o pessoal administrativo estivessem preparados para trabalhar com a nova pedagogia.

As contradições internas à sociedade capitalista, na qual se inseria a escola, passaram a ser objeto de reflexão pelos professores, tanto em sua concepção teórica, quanto em sua prática. O compromisso com a transformação da sociedade permeou as atividades dedicadas à formação continuada dos professores e uma dinâmica diferenciada se instalou nas escolas da Rede Municipal de Ensino de Curitiba.

O $4^{\circ}$ Plano Municipal de Educação, inspirado na pedagogia histórico-crítica, fundamentada nas ideias de Saviani (1986), buscava resgatar a escola como parte do 
sistema social, em seu papel de instrumentalizar as pessoas, mediante a aquisição de conhecimentos sistematizados, para a prática da cidadania. É de se observar que a pedagogia histórico-crítica, voltada à transformação da sociedade, inseria-se numa proposta de governo que, no entanto, admitia a dominação de uma classe social sobre a outra, desde que houvesse a garantia da cidadania para todas. A escola e, nela, os professores, trabalhavam com uma concepção de sociedade que não era aquela em que se inseria o processo educacional do qual participavam naquele momento. A contradição entre as concepções de escola e sociedade era manifesta.

\section{A formação continuada dos docentes no período 1986-1989}

As políticas educacionais definidas para o período correspondente à gestão do prefeito Roberto Requião (PMDB), entre 1986 e 1989, abrangiam três grandes metas: a democratização do conhecimento pela ampliação da oferta escolar, o compromisso da ação escolar com a transformação da sociedade e a integração da ação educativa com as demais ações sociais. Para Requião, a ampliação da oferta escolar era considerada uma "forma de pagamento da dívida social para com a classe trabalhadora" (CURITIBA, 1986, p. 7).

Cada uma dessas metas havia sido dividida em sub-metas, contendo as atividades e os respectivos meses em que deveriam ser desenvolvidas (CURITIBA, 1987).

Do ponto de vista da democratização do conhecimento pela ampliação da oferta escolar, previa-se o aumento das oportunidades de acesso e permanência na escola (meta 1); o apoio técnico-pedagógico às escolas (meta 2); o apoio à estrutura e funcionamento da escola (meta 3); o aperfeiçoamento profissional permanente (meta 4), e o apoio à integração escola-comunidade (meta 5) (CURITIBA, 1987).

Aspectos relativos à instrumentalização do pessoal docente e pedagógicoadministrativo e ao assessoramento na elaboração e reformulação de Planos Curriculares estavam presentes na meta 2 , com sub-metas que especificavam "apoio técnicoandragógico permanente, desde a elaboração do currículo até o processo de realimentação do trabalho junto às classes" (CURITIBA, 1987, p. 13), "assessoramento pedagógico aos professores" (CURITIBA, 1987, p. 20) nas escolas e no Departamento de Educação, a "participação em cursos, encontros, seminários e congressos" (CURITIBA, 1987, p. 21), e o "assessoramento direto ao corpo docente e técnico das escolas com relação à atualização em métodos e técnicas de ensino" (CURITIBA, 1987, p. 23). A“troca de experiências entre professores" (CURITIBA, 1987, p. 36) e o "planejamento, organização, coordenação e realização de encontros para discussão de propostas pedagógicas" (CURITIBA, 1987, p. 45) também estavam previstos.

A meta 3, que propunha a "instrumentalização de supervisores e orientadores para uma atuação mais integrada e efetiva na prática escolar" (CURITIBA, 1987, p. 63), previa a realização de reuniões com coordenadores de área, supervisores e orientadores, cursos de atualização profissional, participação em cursos, reuniões, grupos de estudo, seminários e congressos.

$\mathrm{Na}$ meta 4, especificamente voltada ao aperfeiçoamento profissional permanente, inseriam-se, como sub-metas, inúmeras ações voltadas à formação continuada dos professores:

4.1 Implantação de uma sistemática de atendimento setorial que permita atuação direta do Departamento junto à escola e ao professor. 
4.2 Utilização dos dias da semana móvel para atendimentos setorizados por áreas e por séries.

4.3 Programação de oficinas sobre temas diversos e por solicitação da escola.

4.4 Realização de cursos diversos de capacitação.

4.5 Formação de grupos de estudos sobre temas relevantes e novas metodologias.

4.6 Intercâmbio de experiências entre instituições educacionais (CURITIBA, 1987, p. 7).

Diante dessa proposta educacional, em que o papel do professor assumia nova dimensão, era fundamental desenvolver uma política de aperfeiçoamento sistemático dos docentes, para que pudessem identificar as contradições emanadas das relações sociais e elaborar um currículo escolar em que as necessidades dos alunos fossem contempladas.

Assim, foram previstas atividades que tratavam do planejamento, da oferta de cursos conforme solicitação das escolas ou setores, da organização e da divulgação desses cursos, que eram acompanhados e avaliados pelos cursistas. Estabeleceu-se a semana móvel para atendimentos setorializados e programaram-se oficinas, cursos e a formação de grupos de estudo sobre temas relevantes. Um desses temas era a Constituinte, de cujos trabalhos participariam também "Associações de Pais e Mestres e Associações de Moradores para organização de debates sobre o tema" (CURITIBA, 1987, p. 91).

Para suprir as carências dos docentes nesses aspectos, foram oferecidas inúmeras oportunidades de formação continuada ao corpo docente, por meio da realização de encontros, seminários e congressos, no início de cada semestre e durante o ano letivo. Procurou-se facilitar a participação dos professores mediante a oferta de cursos de forma flexível. Condicionava-se a promoção na carreira docente à participação nos cursos, como maneira de se estimular o professor a investir na sua formação.

Ao se analisar os cursos ofertados verifica-se que poderiam ser de atualização, aperfeiçoamento e especialização. O emprego da atualização como formação docente passava a contemplar o rol de possibilidades oferecido aos professores para que se adaptassem às novas necessidades educacionais. Esse termo foi bastante utilizado na década de 80, no sentido de "pôr em dia os conhecimentos". Com efeito, de acordo com Koogan e Houaiss (1994, p. 88), o ato ou efeito de atualizar-se significa "tornar atual, adaptar às novas necessidades".

Outra inclusão entre os cursos oferecidos era a dos destinados a aperfeiçoamento, com carga horária entre 120 e 359 horas. Essa denominação era utilizada pela legislação vigente e foi mantida.

Quanto aos cursos de especialização, com carga horária igual ou superior a 360 horas, correspondiam aos cursos de pós-graduação que eram oferecidos por instituições de educação superior e às quais um número significativo de docentes acorreu, em busca de uma certificação que lhes facilitasse o acesso a melhores níveis no plano de carreira docente do Município.

As ações voltadas à área pedagógica, no período, dirigiram-se especialmente ao desenvolvimento de uma política de aperfeiçoamento do pessoal, com vistas ao resgate do compromisso político e à competência técnica do professor (MELLO, 1995). Os educadores se ressentiam de sua formação pouco politizada e voltada exclusivamente ao tecnicismo. Cabia-lhes, no entanto, repensar a ação educativa e o seu próprio papel, de forma a que pudessem atuar na descentralização das decisões, em uma relação mais horizontal, envolvendo pais, alunos e professores no processo educacional, valorizando a cultura do aluno e instrumentalizando-o para uma atuação crítica, transformadora e participante. Os professores deveriam também realizar projetos e programas pedagógicos que significassem avanços metodológicos positivos. Era preciso que estivessem preparados 
para esse desafio.

Tais necessidades propiciaram significativo aumento no número de cursos programados e realizados, atendendo-se inclusive às reivindicações apresentadas pelos próprios docentes, nos Seminários Municipais.

A execução dessa nova política, contudo, enfrentou limitações de diferentes nuances: não se dispunha de dados efetivos sobre a qualidade do ensino ministrado nas escolas; os recursos humanos, físicos e financeiros não eram suficientes para concretização das ações programadas; haviaentraves na liberação de recursos oriundos de projetos estaduais e federais; era necessário superar a burocracia administrativa, que retardava ou impossibilitava decisões; e, por último, enfrentava-se a pequena participação dos pais na eleição dos diretores das escolas (CURITIBA, 1987).

Não obstante essas dificuldades, dos documentos compulsados pode-se inferir que foram cumpridas as metas e sub-metas estabelecidas para o período e que tratavam do apoio à instrumentalização do pessoal docente e pedagógico-administrativo, do assessoramento pedagógico aos professores, com a oferta de cursos, encontros, seminários e congressos, nos quais eram discutidas as implicações da pedagogia histórico-crítica na educação municipal.

\section{CONSIDERAÇÕES FINAIS}

Numa sociedade que procurava superar suas contradições na área educacional, mas que tinha seu modo de produção calcado no capitalismo, a formação continuada de professores de acordo com a pedagogia histórico-crítica suscitou discussões, reflexões e estudos tanto em sua concepção teórica, quanto em sua prática.

Na gestão de Roberto Requião, com a implantação da pedagogia histórico-crítica, a responsabilidade da escola em relação ao saber sistematizado, sua transmissão e assimilação era considerada relevante e, para bem desempenhar essa tarefa, os professores deveriam possuir competência técnica e política, envolvendo o domínio adequado do saber escolar a ser transmitido, um entendimento das múltiplas relações entre os vários aspectos da escola, uma compreensão das relações entre o preparo técnico, a organização da escola e os resultados de sua ação, bem como uma compreensão mais ampla das relações entre a escola e a sociedade (SAVIANI, 1986).

Foram esses os fundamentos teóricos que justificaram a ênfase na formação continuada dos professores da Rede Municipal de Ensino, que necessitavam discutir não apenas os aspectos técnicos de sua prática, mas também a compreensão da história, partindo das condições materiais da existência humana (GRAMSCI, 1991).

Considerando-se as metas e sub-metas propostas na área educacional para o período correspondente à gestão do prefeito Roberto Requião (1986-1989), verifica-se que a oferta de formação em encontros, treinamento, atualização, aperfeiçoamento e especialização era bastante diversificada e buscava se inserir nas disponibilidades e no cotidiano dos professores participantes. Além disso, atendia às reivindicações emanadas dos próprios docentes, a partir das necessidades sentidas na prática pedagógica. Estavam subjacentes a essa formação continuada o papel político do professor e sua valorização como elemento fundamental na transformação da sociedade, o que corroborava a ênfase no desenvolvimento das competências técnica e política.

Analisando-se o período de uma forma geral, pode-se inferir que, apesar das dificuldades, o papel político do professor e sua valorização foram consignados. 


\section{REFERÊNCIAS}

CURITIBA. Relatório geral de atividades. Divisão de Treinamento Pedagógico. Diretoria de Educação. Prefeitura Municipal de Curitiba. Curitiba: Prefeitura Municipal de Curitiba, 1983.

Plano de educação do município. Gestão 1986/1988. Curitiba: Prefeitura Municipal de Curitiba, 1986.

Políticas (?). Secretaria Municipal da Educação. Prefeitura Municipal de Curitiba. Curitiba: Prefeitura Municipal de Curitiba, 1987.

DUARTE, N. Vigotski e o "aprender a aprender": crítica às apropriações neoliberais e pós-modernas da teoria vigotskiana.Campinas, SP: Autores Associados, 2001.

FARGE, A. O sabor do arquivo. Trad. Fátima Murad. São Paulo: Editora da Universidade de São Paulo, 2009.

GOHN, M. da G. Movimentos sociais e luta pela moradia. São Paulo: Loyola, 1991.

GRAMSCI, A. Os intelectuais e a organização da cultura. Tradução de Carlos Nelson Coutinho. Rio de Janeiro: Civilização Brasileira, 1991.

KOOGAN/HOUAISS. Enciclopédia e dicionário. Ilustrado. Rio de Janeiro: Edições Delta, 1994.

LÜDKE, M.; ANDRÉ, M. E. D. A pesquisa em educação: abordagens qualitativas. São Paulo: EPU, 1986.

MELlo, G. N. de. Magistério de $\mathbf{1}^{\mathbf{0}}$ grau: da competência técnica ao compromisso político. São Paulo: Cortez, 1995.

MIGUEL, M. E. B.; VIEIRA, A. M. D. P. As políticas educacionais da Rede Municipal de Educação de Curitiba e a implantação de novas práticas nas escolas (1963-1996). CONGRESSO BRASILEIRO DE HISTÓRIA DA EDUCAÇÃO, 4, 2006, Goiânia. Anais... Goiânia, 2006. 1 CD-ROM.

PROST, A. Doze lições sobre a história. Tradução de Guilherme João de Freitas Teixeira. Belo Horizonte: Autêntica Editora, 2014.

SAVIANI, D. Educação: do senso comum à consciência filosófica. São Paulo: Cortez, 1986.

Pedagogia histórico-crítica: primeiras aproximações. Campinas, SP: Autores Associados, 2008. (Coleção educação contemporânea). 
TOMACHESKI, E. G. B. A trajetória da educação matemática na Rede Municipal de Ensino de Curitiba: do currículo pensado ao vivido. Dissertação (Mestrado em Educação). Pontifícia Universidade Católica do Paraná. 2003.

i PUCPR alboni@alboni.com 